\title{
CORRELAÇÕES GENOTÍPICAS, FENOTÍPICAS E AMBIENTAIS ENTRE CARACTERES DE MAMONEIRA
}

\author{
Genotypic, phenotypic and environmental correlations among castor bean variables \\ Helen Cristina de Arruda Rodrigues ${ }^{1}$, Samuel Pereira de Carvalho ${ }^{2}$, Alexandre Alves de Carvalho ${ }^{2}$, \\ Carlos Eduardo Magalhães dos Santos ${ }^{3}$, José Luiz Sandes de Carvalho Filho ${ }^{2}$
}

\begin{abstract}
RESUMO
Um dos grandes desafios atuais da pesquisa agrícola é a produção de cultivares melhoradas de mamoneira, com estabilidade genética, alta qualidade e potencial produtivo. Objetivou-se, no presente trabalho, estimar as correlações genotípica, fenotípica e de ambiente entre caracteres de mamona para facilitar a caracterização dos acessos. Foram avaliados em Lavras, MG, no delineamento de blocos casualizados com três repetições, quinze acessos de mamona. Os caracteres avaliados foram altura da planta, altura do caule, número de internódios, diâmetro do caule, número de cachos, estande final e peso de 100 sementes. Observou-se que houve correlação fenotípica positiva do número de internódios e altura do caule, altura do caule e altura da planta, altura da planta e diâmetro do caule e por fim entre diâmetro do caule e peso de 100 sementes. Houve também correlação ambiental positiva entre as correlações altura de caule e altura de planta, altura de planta e diâmetro do caule, altura da planta e estande final e diâmetro do caule e número de cachos, concluindo que as correlações estimadas possibilitaram conhecer as associações entre os caracteres, fornecendo importantes informações para o estabelecimento de um plano de melhoramento genético da mamona, a partir dos acessos avaliados.
\end{abstract}

Termos para indexação: Ricinus communis L., divergência genética, variabilidade.

\begin{abstract}
One of the great current challenges of agricultural research is the production of improved castor bean cultivars, with genetic stability, high quality and high yielding potential. The objective this work was to estimate genotypic, phenotypic and environmental correlations among traits of the castor bean plant to make the characterization of the accessions easy. They were evaluated in Lavras, MG, Brazil, in a randomized block design with three replicates, fifteen castor bean accessions. The traits evaluated were: plant height, stem height, number of nodes, stem diameter, final number of clusters, stand and 100-seed weight. It was observed that there was a positive phenotypic correlation of the node number and stem height, stem height and plant height, plant height and stem diameter and at last between stem diameter and 100-seed weight. There was also a positive environmental correlation among the correlations stem height and plant height, plant height and stem diameter, plant height and final stand and stem diameter and number of clusters, concluding that the estimated correlations make it possible to know the associations among the traits, giving important information to the establishment of a genetic improvement plan of castor bean from the accessions evaluated.
\end{abstract}

Index terms: Ricinus communis L., genetic divergence, variability.

(Recebido em 5 de junho de 2009 e aprovado em 17 de março de 2010)

\section{INTRODUÇÃo}

A mamoneira (Ricinus communis L.) é uma oleaginosa de elevado valor socioeconômico e fonte de divisas para o país. Seus produtos e subprodutos são utilizados na indústria ou na agricultura, além de apresentar perspectivas de uso como fonte energética sob a forma de biodiesel (Costa et al., 2006).

De acordo com Oliveira \& Zanotto (2008), para minimizar a dificuldade de produção em escala industrial é imprescindível o desenvolvimento de materiais genéticos que atendem como, por exemplo, o porte adequado para facilitar a colheita e a uniformização na maturação, visando a utilização de alta tecnologia que possibilitem a produção dessa oleaginosa em maior escala. É nesse sentido, que o melhoramento de plantas contribui para o crescimento das produções agrícolas, principalmente por causa da variabilidade existente entre as culturas.

No caso da mamona, há uma variabilidade muito grande, segundo Azevedo et al. (1997), especificamente quanto ao porte; à coloração e tamanho da folhagem e do caule; ao formato, tamanho, peso e coloração da semente; a cor e ao conteúdo de óleo; a tolerância à pragas e doenças e a estresse ambiental. Nesse contexto, a caracterização e avaliação são consideradas essenciais tanto para

'Universidade Estadual Paulista "Júlio de Mesquita Filho"/UNESP - Departamento de Tecnologia - Via de Acesso Professor Paulo Donato Castellane $\mathrm{s} / \mathrm{n}$ - 14870-000 - Jaboticabal, SP - helenarruda11@gmail.com

'Universidade Federal de Lavras/UFLA - Departamento de Agricultura/DAG - Lavras, MG

${ }^{3}$ Universidade Federal de Viçosa/UFV - Rio Paranaíba, MG 
estabelecer diferenças ou semelhanças entre acessos de germoplasma, como para estimular sua utilização para resgatar o desenvolvimento das culturas. Essa variabilidade observada em características botânicas e agronômicas deve ser conhecida e conservada porque pode se tornar fonte importante de genes para os programas de melhoramento. Para Falconer (1987), a variabilidade genética de uma população segregante, necessária nos processos seletivos, é resultante da divergência genética entre os parentais envolvidos nos cruzamentos.

A divergência genética é um dos mais importantes parâmetros avaliados por melhoristas de plantas na fase inicial de um programa de melhoramento genético. Em programas que envolvem hibridações, esses estudos fornecem parâmetros para identificação de genitores que, quando cruzados, possibilitam maior efeito heterótico na progênie (Samal \& Jagadev, 1996; Pandey \& Dobhal, 1997; Carvalho et al., 2003).

O estudo e a análise da diversidade genética destinamse à identificação de genitores que, quando cruzados, proporcionem, em suas gerações segregantes, o aparecimento de transgressivos e a obtenção de híbridos com maior efeito heterótico (Cruz et al., 1994). Em decorrer disso, a avaliação de caracteres agronômicos é de grande importância para se conhecer o comportamento das plantas até a fase de colheita. Com base nisso, o melhorista poderá selecionar acessos promissores para posteriores cruzamentos e obtenção de novas cultivares comerciais (Lessa et al., 2009).

Segundo Ferreira et al. (2003), geralmente, os programas de melhoramento têm por finalidade obter cultivares aprimoradas para um conjunto de caracteres. Por isso, o conhecimento da natureza e magnitude das correlações entre os caracteres de interesse é de fundamental importância. As relações existentes entre os caracteres são, em geral, avaliadas por meio das correlações genotípicas, fenotípicas e de ambiente. A correlação fenotípica é estimada diretamente de medidas fenotípicas, sendo resultante, portanto, de causas genéticas e ambientais. Apenas a correlação genotípica, que corresponde à porção genética da correlação fenotípica, é empregada para orientar programas de melhoramento, por ser a única de natureza herdável.

Objetivou-se, nesse trabalho, distinguir os acessos dissimilares e estimar as correlações genotípicas, fenotípicas e de ambiente.

\section{MATERIAL E MÉTODOS}

$\mathrm{O}$ trabalho foi conduzido na área experimental da Universidade Federal de Lavras, Lavras, Minas Gerais, em Latossolo Vermelho distroférrico. O clima da região é temperado suave (mesotérmico), tipo $\mathrm{Cwb}$. A região está localizada a uma altitude de 913 metros, $21^{\circ} 14^{\prime} 06^{\prime \prime}$ latitude
S e $45^{\circ} 00^{\prime} 00^{\prime}$ ' longitude $\mathrm{O}$, tem precipitação média anual de 1493,2 mm, ocorrendo uma maior concentração entre os meses de novembro e fevereiro, sua temperatura média anual é $19,3^{\circ} \mathrm{C}$ e a umidade relativa do ar é $80 \%$ (Castro Neto \& Silveira, 1981).

As sementes de cada acesso de mamona utilizadas foram obtidas de várias localidades de Minas Gerais, em que, cada acesso continha apenas sementes da mesma localidade, sendo utilizados quinze acessos.

O plantio foi realizado por mudas preestabelecidas, ou seja, as sementes foram semeadas em bandejas com areia até a protusão da radícula (aproximadamente 5 dias) em casa de vegetação e depois transplantadas para os recipientes com o substrato, para um viveiro com sombrite $50 \%$ de luminosidade. Utilizaram-se tubetes com capacidade de $55 \mathrm{~cm}^{3}$, e como substrato foi usado o Plantmax-café ${ }^{\circledast}$, que possui as seguintes características: $\mathrm{pH}$ [água] $-4,7$; M.O. $-578 \mathrm{~g} / \mathrm{kg}$; C.O. $-321 \mathrm{~g} / \mathrm{kg} ; \mathrm{N}-8,12 \mathrm{~g} / \mathrm{kg} ; \mathrm{P}-2,81 \mathrm{~g} / \mathrm{kg} ; \mathrm{K}-4,80 \mathrm{~g} / \mathrm{kg}$; RMT - $422 \mathrm{~g} / \mathrm{kg}$; umidade à $65^{\circ} \mathrm{C}[\%]-67,22$; condutividade elétrica $[\mu \mathrm{S}]-3,33$. Ficaram aproximadamente mais 20 dias. Foram utilizadas sementes de quinze acessos, sendo esses os tratamentos.

Antes de realizar o plantio, a área foi gradeada $\mathrm{e}$ depois sulcada, com espaçamento de 1,00 m entre plantas e estrelinhas. Posteriormente, realizou-se adubação com NPK, na proporção de 8: 28: 16 (300 kg/ha). O plantio foi realizado em meados de fevereiro de 2008 , em que as mudas prontas foram levadas para campo.

O delineamento estatístico foi de blocos casualizados, consistindo-se de três blocos, sendo cada bloco constituído de 25 plantas por linha, perfazendo uma parcela, de um mesmo acesso, sorteado ao acaso. Foi utilizada bordadura com a cultivar Mirante 10 .

Foram coletados dados de sete variáveis quantitativas: a) Altura da planta (AP) - média das alturas das plantas da parcela em m; b) altura do caule (AC) altura média do caule acima do solo, em m; c) diâmetro do caule (DC) - média dos diâmetros dos caules tomada na região mediana, em cm; d) número de internódios (NI) - média dos números de internódios das plantas da parcela; e) número de cacho (NC) - média dos números de cacho, por planta da parcela; f) peso de 100 sementes (PS); g) estande final (EF) - número de plantas ao final do ciclo.

Os dados obtidos foram submetidos à análise de variância e sua médias comparadas pelo teste de ScottKnott, ao nível de $5 \%$ de probabilidade.

As estimativas dos coeficientes de correlação genotípica $(r G)$, fenotípica $(r F)$ e de ambiente $(r E)$ foram obtidas mediante análises de covariâncias, combinando os dados das sete caracteres, em todas as formas possíveis 
(Cruz \& Regazzi, 1994). As análises estatísticas foram realizadas no programa GENES (Cruz, 2006).

\section{RESULTADOS E DISCUSSÃO}

De acordo com a análise de variância, houve diferença significativa para todos os caracteres, exceto para estande final (EF). Na Tabela 1, pode-se observar que as médias somente não diferem significativamente para o estande final, confirmando resultados obtidos pelo teste $\mathrm{F}$, indicando a existência de divergência genética entre as cultivares. O coeficiente de variação foi satisfatório em todos os caracteres, sugerindo eficiente controle do efeito de ambiente e, consequentemente, maior confiabilidade nos dados. Esses resultados assemelham-se com os de Bahia et al. (2008), em que avaliando a divergência genética entre 5 cultivares de mamona, os autores verificaram diferença significativa para a maioria dos caracteres, à exceção do estande final (EST), necessitando também avaliar as médias separadamente, pelo teste de Scott-Knott.

Em relação à mesma tabela, pode-se observar a formação de, pelo menos, dois grupos pelo teste de Scott-
Knott, em quase todos os caracteres avaliados. Observase ainda a formação de 3 grupos, quanto ao caracter DC, 4 grupos ao caracter NI e 15 grupos, quanto ao caracter PS.

A diversidade fenotípica foi constatada entre os genótipos sendo inclusive, facilmente visualizada nas características agronômicas utilizadas neste trabalho.

Os acessos 10, 12 e 15, alcançaram os melhores desempenhos em quase todos os componentes de produção: altura das plantas, altura do caule, diâmetro do caule e número de cachos. Para número de internódios, o acesso 11 apresentou o melhor desempenho e para peso de 100 sementes, o acesso 12 foi melhor, isoladamente.

A análise de agrupamentos engloba uma variedade de técnicas e algoritmos, cujo objetivo principal é a descoberta de grupos naturais nos itens ou variáveis, sendo considerada uma importante técnica exploratória, na qual nenhuma suposição é feita a respeito do número de grupos ou de sua estrutura (Totti et al., 2001). Em decorrer disso, o método de agrupamento é de grande importância para o estudo da divergência genética entre acessos de plantas.

Tabela 1 - Médias das características agronômicas (C.A.) de quinze acessos de mamoneira, avaliadas em Lavras, MG ${ }^{1}$, 2008.

\begin{tabular}{cccccccc}
\hline C. A. & AP & AC & DC & NI & NC & PS & EF \\
\hline Acessos & & & & & & & \\
\hline 1 & $0,90 \mathrm{~b}$ & $0,68 \mathrm{~b}$ & $1,83 \mathrm{c}$ & $14,00 \mathrm{c}$ & $1,73 \mathrm{~b}$ & $33,07 \mathrm{o}$ & $180 \mathrm{a}$ \\
2 & $1,53 \mathrm{a}$ & $1,04 \mathrm{~b}$ & $3,10 \mathrm{~b}$ & $16,00 \mathrm{~b}$ & $4,67 \mathrm{a}$ & $38,30 \mathrm{n}$ & $18,33 \mathrm{a}$ \\
3 & $1,90 \mathrm{a}$ & $0,86 \mathrm{~b}$ & $3,23 \mathrm{~b}$ & $15,33 \mathrm{~b}$ & $4,13 \mathrm{a}$ & $57,30 \mathrm{~b}$ & $17,33 \mathrm{a}$ \\
4 & $1,90 \mathrm{a}$ & $0,95 \mathrm{~b}$ & $3,60 \mathrm{a}$ & $16,00 \mathrm{~b}$ & $3,13 \mathrm{~b}$ & $43,40 \mathrm{~m}$ & $16,33 \mathrm{a}$ \\
5 & $1,56 \mathrm{a}$ & $1,00 \mathrm{~b}$ & $3,77 \mathrm{a}$ & $14,33 \mathrm{c}$ & $3,27 \mathrm{~b}$ & $45,90 \mathrm{i}$ & $12,67 \mathrm{a}$ \\
6 & $1,77 \mathrm{a}$ & $0,97 \mathrm{~b}$ & $3,77 \mathrm{a}$ & $14,33 \mathrm{c}$ & $2,60 \mathrm{~b}$ & $49,10 \mathrm{~h}$ & $12,67 \mathrm{a}$ \\
7 & $1,80 \mathrm{a}$ & $0,99 \mathrm{~b}$ & $3,87 \mathrm{a}$ & $16,00 \mathrm{~b}$ & $3,40 \mathrm{~b}$ & $52,90 \mathrm{c}$ & $18,33 \mathrm{a}$ \\
8 & $1,73 \mathrm{a}$ & $0,91 \mathrm{~b}$ & $3,77 \mathrm{a}$ & $14,00 \mathrm{c}$ & $3,20 \mathrm{~b}$ & $52,60 \mathrm{~d}$ & $15,33 \mathrm{a}$ \\
9 & $1,90 \mathrm{a}$ & $0,90 \mathrm{~b}$ & $3,87 \mathrm{a}$ & $16,33 \mathrm{~b}$ & $3,67 \mathrm{~b}$ & $45,50 \mathrm{j}$ & $16,33 \mathrm{a}$ \\
10 & $2,30 \mathrm{a}$ & $1,41 \mathrm{a}$ & $3,73 \mathrm{a}$ & $15,00 \mathrm{~b}$ & $4,40 \mathrm{a}$ & $51,90 \mathrm{e}$ & $19,33 \mathrm{a}$ \\
11 & $2,00 \mathrm{a}$ & $1,37 \mathrm{a}$ & $2,97 \mathrm{~b}$ & $19,00 \mathrm{a}$ & $3,00 \mathrm{~b}$ & 43,801 & $18,67 \mathrm{a}$ \\
12 & $1,93 \mathrm{a}$ & $0,85 \mathrm{~b}$ & $3,53 \mathrm{a}$ & $15,33 \mathrm{~b}$ & $4,07 \mathrm{a}$ & $57,90 \mathrm{a}$ & $16,33 \mathrm{a}$ \\
13 & $1,60 \mathrm{a}$ & $0,63 \mathrm{~b}$ & $3,17 \mathrm{~b}$ & $12,00 \mathrm{~d}$ & $5,80 \mathrm{a}$ & $50,20 \mathrm{f}$ & $17,33 \mathrm{a}$ \\
14 & $1,90 \mathrm{a}$ & $0,92 \mathrm{~b}$ & $3,90 \mathrm{a}$ & $15,33 \mathrm{~b}$ & $4,60 \mathrm{a}$ & $44,90 \mathrm{k}$ & $17,67 \mathrm{a}$ \\
15 & $2,03 \mathrm{a}$ & $1,27 \mathrm{a}$ & $3,57 \mathrm{a}$ & $15,33 \mathrm{~b}$ & $4,33 \mathrm{a}$ & $50,10 \mathrm{~g}$ & $20,33 \mathrm{a}$ \\
\hline CV $(\%)$ & 11,87 & 17,66 & 7,60 & 4,70 & 12,24 & 0,03 & 15,82 \\
\hline
\end{tabular}

${ }^{1}$ AP: Altura de plantas; AC: Altura do caule; DC: Diâmetro do caule; NI: Número de internódios por planta; NC: Número de cachos por planta; PS: Peso de 100 sementes; EF: Estande final; médias seguidas da mesma letra, na coluna, não diferem entre si pelo teste de Scott-Knott, a 5\% de probabilidade. 
Em relação aos coeficientes $(r G)$ e $(r F)$, foi verificada uma grande similaridade entre os pares de caracteres, em relação aos sinais, a magnitude e o nível de significância, com exceção apenas das correlações entre NI e AC, $\operatorname{com} r G=0,6418^{\mathrm{NS}}$ e $r F=0,6026^{*}$; AC e AP, $\operatorname{com} r G=0,7389^{\mathrm{NS}} \mathrm{e} r F=0,7162^{* *}$; AP e DC, $\operatorname{com} r G=0,7567^{\mathrm{NS}}$ e $r F=0,7252^{* *}$ e por fim a correlação DC e PS, com $r G=0,6023^{\mathrm{NS}}$ e $r F=0,5787^{*}$ (Tabela 2).

Em 76,19\% dos pares de caracteres, as correlações genotípicas foram superiores às correlações fenotípicas, assim como estas duas, em $80,95 \%$ dos casos foram superiores às correlações de ambiente. Verificou-se também que, nas 21 combinações possíveis entre os sete caracteres, em apenas quatro a correlação ambiental foi superior à genotípica. A correlação de ambiente, para a maioria dos pares de caracteres, foi reduzida, ou seja, menor que 0,5 , constatando-se que houve maior contribuição dos fatores genéticos em relação aos fatores ambientais nas correlações entre os caracteres. Esses resultados estão de acordo com Ferreira et al. (2003), que, trabalhando com correlações genotípicas, fenotípicas e de ambiente entre dez caracteres de melancia, verificaram que, em 95,5\% dos pares de caracteres, as correlações genotípicas foram iguais ou superiores às correlações fenotípicas, assim como estas duas, em 82,2\% dos casos foram superiores às correlações de ambiente. Verificou-se também que, nas 45 combinações possíveis entre os dez caracteres, em apenas oito a correlação ambiental foi superior à genotípica.

De acordo com a Tabela 2, para as correlações entre NI e AC, e DC e PS, a correlação fenotípica foi significativa ( $r F=0,6026 ; r F=0,5787$, respectivamente), indicando que houve uma correlação positiva entre esses caracteres, ou seja, quanto maior for o número de internódios numa planta, maior também será a altura do caule e quanto maior o diâmetro do caule, o peso de 100 sementes foi maior. Assim aconteceu, basicamente, a mesma coisa para as correlações entre AC e AP, e AP e $\mathrm{DC}$, que apresentaram uma grande correlação positiva diretamente proporcional ( $r F=0,7162$ e $r E=0,6163$; $r F=0,7252$ e $r E=0,5757$, respectivamente), além de um forte indício de interação do ambiente, para essas

Tabela 2 - Coeficientes de correlação genotípica $(r G)$, fenotípica $(r F)$ e ambiental $(r E)$ entre sete caracteres avaliados de mamona. UFLA, Lavras, MG, 2008.

\begin{tabular}{|c|c|c|c|c|c|c|c|c|}
\hline Caracteres & $\bar{r}$ & NI & $\mathrm{AC}$ & $\mathrm{AP}$ & $\mathrm{DC}$ & $\mathrm{NC}$ & $\overline{E F}$ & PS \\
\hline \multirow{3}{*}{ NI } & $\bar{G}$ & 1 & $0.6418^{\mathrm{NS}}$ & $0.4774^{\mathrm{NS}}$ & $0.0776^{\mathrm{NS}}$ & $-0.2504^{\mathrm{NS}}$ & $0.4972^{\mathrm{NS}}$ & $-0.1338^{\mathrm{NS}}$ \\
\hline & $\mathrm{F}$ & & $0.6026^{*}$ & $0.4243^{\mathrm{NS}}$ & $0.0688^{\mathrm{NS}}$ & $-0.2255^{\mathrm{NS}}$ & $0.3120^{\mathrm{NS}}$ & $-0.1288^{\mathrm{NS}}$ \\
\hline & $\mathrm{E}$ & & $0.3871^{\mathrm{NS}}$ & $0.0788^{\mathrm{NS}}$ & $-0.0388^{\mathrm{NS}}$ & $-0.1575^{\mathrm{NS}}$ & $-0.1187^{\mathrm{NS}}$ & $-0.2436^{\mathrm{NS}}$ \\
\hline \multirow{3}{*}{$\mathrm{AC}$} & $\mathrm{G}$ & & 1 & $0.7389^{\mathrm{NS}}$ & $0.3217^{\mathrm{NS}}$ & $0.0471^{\mathrm{NS}}$ & $0.5076^{\mathrm{NS}}$ & $0.0749^{\mathrm{NS}}$ \\
\hline & $\mathrm{F}$ & & & $0.7162 * *$ & $0.2792^{\mathrm{NS}}$ & $0.0113^{\mathrm{NS}}$ & $0.3578^{\mathrm{NS}}$ & $0.0675^{\mathrm{NS}}$ \\
\hline & $\mathrm{E}$ & & & $0.6163^{*}$ & $0.0024^{\mathrm{NS}}$ & $-0.1036^{\mathrm{NS}}$ & $0.1207^{\mathrm{NS}}$ & $-0.1936^{\mathrm{NS}}$ \\
\hline \multirow{3}{*}{ AP } & $\mathrm{G}$ & & & 1 & $0.7567^{\mathrm{NS}}$ & $0.5358^{\mathrm{NS}}$ & $0.1213^{\mathrm{NS}}$ & $0.5369^{\mathrm{NS}}$ \\
\hline & $\mathrm{F}$ & & & & $0.7252 * *$ & $0.4666^{\mathrm{NS}}$ & $0.1038^{\mathrm{NS}}$ & $0.4851^{\mathrm{NS}}$ \\
\hline & $\mathrm{E}$ & & & & $0.5757^{*}$ & $0.2589^{\mathrm{NS}}$ & $0.0884 *$ & $-0.1150^{\mathrm{NS}}$ \\
\hline \multirow{3}{*}{ DC } & $\mathrm{G}$ & & & & 1 & $0.3270^{\mathrm{NS}}$ & $-0.4736^{\mathrm{NS}}$ & $0.6023^{\mathrm{NS}}$ \\
\hline & $\mathrm{F}$ & & & & & $0.3322^{\mathrm{NS}}$ & $-0.2921^{\mathrm{NS}}$ & $0.5787 *$ \\
\hline & $\mathrm{E}$ & & & & & $0.4549 *$ & $0.1342^{\mathrm{NS}}$ & $0.1967^{\mathrm{NS}}$ \\
\hline \multirow{3}{*}{$\mathrm{NC}$} & $\bar{G}$ & & & & & 1 & $0.5234^{\mathrm{NS}}$ & $0.4579^{\mathrm{NS}}$ \\
\hline & $\mathrm{F}$ & & & & & & $0.3447^{\mathrm{NS}}$ & $0.3843^{\mathrm{NS}}$ \\
\hline & $\mathrm{E}$ & & & & & & $0.0957^{\mathrm{NS}}$ & $0.0404^{\mathrm{NS}}$ \\
\hline \multirow{3}{*}{$\mathrm{EF}$} & $\mathrm{G}$ & & & & & & 1 & $-0.1093^{\mathrm{NS}}$ \\
\hline & $\mathrm{F}$ & & & & & & & $-0.0766^{\mathrm{NS}}$ \\
\hline & $\mathrm{E}$ & & & & & & & $-0.0873^{\mathrm{NS}}$ \\
\hline
\end{tabular}

Significativo ao nível de $1 \%$ de probabilidade $(* *), 5 \%$ de probabilidade $(*)$ e não significativo ao nível de $5 \%$ de probabilidade (NS), pelo teste de F. ++,+ : Significativo a 1 e 5\%, respectivamente, pelo método de bootstrap com 5000 simulações. NI = Número de internódios; AC = altura do caule; $\mathrm{AP}=$ altura da planta; $\mathrm{DC}=$ diâmetro do caule; $\mathrm{NC}=$ número de cachos; $\mathrm{EF}=$ estande final; $\mathrm{PS}=$ peso de 100 sementes. 
correlações. Já para as correlações DC e NC, e AP e EF apenas a correlação de ambiente foi significativa ( $r E=0,4549$, $r E=0,0884$, respectivamente), indicando que pode haver interação de ambiente, para esses caracteres.

As relações existentes entre os caracteres são, em geral, avaliadas por meio da estimativa e do sinal dos coeficientes de correlação genotípica, fenotípica e de ambiente. Estudos das associações entre caracteres fornecem informações importantes para o melhoramento genético, como a quantificação da porção de correlação fenotípica que é devida à causas genéticas e à mensuração de ganhos indiretos devido à seleção efetuada em caracteres correlacionados (Vencovsky \& Barriga, 1992).

Neste trabalho, observamos que $100,80,95$ e $80,95 \%$ das estimativas dos coeficientes de correlação genotípica, fenotípica e ambiental, respectivamente, não foram significativas, indicando que apesar da baixa correlação entre os caracteres, eles agem independentes. Resultados contrários foram observados por Nunes et al. (2008), que verificaram que 61,90 e $66,66 \%$ das estimativas dos coeficientes de correlação genotípica e fenotípica foram significativas, enquanto apenas $28,57 \%$ das estimativas para os coeficientes de correlação ambiental foram significativas.

Quando há correlação significativa entre dois caracteres, é possível obter ganho em um deles por meio da seleção indireta do outro. Isso é vantajoso, principalmente, quando um caráter de elevado valor econômico possui baixa herdabilidade e, ou, difícil avaliação, quando comparado a outro caráter que está associado a ele. Dessa forma, a seleção é feita no caráter que apresenta alta herdabilidade e/ou fácil avaliação, visando melhorar o outro (Nunes et al., 2008).

\section{CONCLUSÕES}

As correlações estimadas possibilitaram conhecer as associações entre os caracteres, fornecendo importantes informações para o estabelecimento de um plano de melhoramento genético da mamona, a partir dos acessos avaliados.

Há correlações fenotípicas positivas diretamente proporcionais entre número de internódio e altura de caule, altura de caule e altura de plantas, altura de plantas e diâmetro do caule e diâmetro de caule e peso de 100 sementes.

Há correlações ambientais positivas entre altura do caule e altura da planta, altura da planta e diâmetro do caule, altura da planta e estande final e diâmetro do caule e número de cachos, por planta.

\section{AGRADECIMENTOS}

À Capes, pela concessão da bolsa de estudos. em projetos.

Ao CNPq, FAPEMIG e FINEP, pelo apoio financeiro

\section{REFERÊNCIAS BIBLIOGRÁFICAS}

AZEVEDO, D.M.P.; LIMA, E.F.; BATISTA, F.A.S. Recomendações técnicas para o cultivo da mamoneira (Ricinus communis L.) no Nordeste do Brasil. Campina Grande: MAARA/Embrapa-CNPA, 1997. 52p. (Circular técnico, 25).

BAHIA, H.F.; SILVA, S.A.; FERNANDEZ, L.G.; LEDO, C.A.S.; MOREIRA, R.F.C. Divergência genética entre cinco cultivares de mamoneira. Pesquisa Agropecuária Brasileira, Brasília, v.43, n.3, p.357-362, mar. 2008.

CARVALHO, L.P. de; LANZA, M.A.; FALLIERI, J.; SANTOS, J.W. dos. Análise da divergência genética entre acessos de banco ativo de germoplasma de algodão. Pesquisa Agropecuária Brasileira, Brasília, v.38, n.10, p.1149-1155, out. 2003.

CASTRO NETO, P.; SILVEIRA, S.V. Precipitação provável para Lavras, região Sul de Minas Gerais, baseada na função de distribuição de probabilidade gama: 1, período mensais. Ciência e Prática, Lavras, v.5, n.2, p.144-151, jul./dez. 1981

COSTA, M.N.; PEREIRA, W.E.; BRUNO, R.L.A.; FREIRE, E.C.; NÓBREGA, M.B.M.; MILANI, M.; OLIVEIRA, A.P. Divergência genética entre acessos e cultivares de mamoneira por meio de estatística multivariada. Pesquisa Agropecuária Brasileira, Brasília, v.41, n.11, p.1617-1622, nov. 2006.

CRUZ, C.D. Programa GENES versão windows: aplicativo computacional em genética e estatística. Viçosa, MG: UFV, 2007. 642p.

CRUZ, C.D.; CARVALHO, S.P.; VENCOVSKY, R. Estudos sobre divergência genética: I., fatores que afetam a predição do comportamento de híbridos. Revista Ceres, Viçosa, v.41, n.234, p.178-182, mar./abr. 1994.

CRUZ, C.D.; REGAZZI, A.J. Modelos biométricos aplicados ao melhoramento genético. Viçosa, MG: UFV, 1994. 390p.

FALCONER, D.S. Introdução à genética quantitativa. Viçosa, MG: UFV, 1987. 279p. 
FERREIRA, M.A.J.F.; QUEIROZ, M.A.; BRAZ, L.T.; VENCOVSKY, R. Correlações genotípicas, fenotípicas e de ambiente entre dez caracteres de melancia e suas implicações para o melhoramento genético.

Horticultura Brasileira, Brasília, v.21, n.3, p.438-442, jul./set. 2003.

LESSA, L.S., LEDO, C.A. da S., SILVA, S. de O. e, PEIXOTO, C.P. Avaliação agronômica em híbridos diplóides (AA) de bananeira. Ciência e Agrotecnologia, Lavras, v.33, Edição Especial, p.1716-1721, 2009.

NUNES, G.H.S.; BARROS, A.K.A.; QUEIROZ, M.A.; SILVA, R.A.; LIMA, L.L. Correlações entre características de meloeiro. Caatinga, Mossoró, v.21, n.1, p.107-112, jan./mar. 2008.

OLIVEIRA, I.J. de; ZANOTTO, M.D. Eficiência da seleção recorrente para redução da estatura de plantas em mamoneira (Ricinus communis L.). Ciência e
Agrotecnologia, Lavras, v.32, n.4, p.1107-1112, jul./ago., 2008.

PANDEY, G.; DOBHAL, V.K. Multivariate analysis in taro (Colocasia esculenta L.). Indian Journal of Genetics \& Plant Breeding, New Delhi, v.57, n.3, p.262-265, 1997.

SAMAL, K.M.; JAGADEV, P.N. Genetic divergence among chickpea cultivars. Indian Journal of

Genetics \& Plant Breeding, New Delhi, v.56, n.1, p.86-88, 1996.

TOTTI, R.; VENCOVSKY, R.; BATISTA, L.A.R. Utilização de métodos de agrupamentos hierárquicos em acessos de Paspalum (Graminea (Poaceae)). Semina: Ciências Exatas e Tecnológicas, Londrina, v.22, p.25-35, dez. 2001.

VENCOVSKY, R.; BARRIGA, P. Genética biométrica no fitomelhoramento. Ribeirão Preto: Sociedade Brasileira de Genética, 1992. 486p. 